\title{
PERFORMANCE ANALYSIS OF A BRUSHLESS DOUBLY-FED SINGLE-PHASE INDUCTION MACHINE
}

\author{
Mahmoud M. Khater \\ Department of Electrical Engineering, Faculty of Engineering, \\ Minoufiya University, Shebin El-Kom, Egypt
}

\begin{abstract}
This paper introduces an alternative configuration for Brushless Doubly Fed Machine (BDFM). The proposed machine is a single-frame induction machine provided with two electrically perpendicular sets of stator windings having the same number of poles with no direct transformer coupling between them. The rotor is a conventional squirrel cage with no conditions imposed on its design and represents the only path for power transfer between the two sets of stator windings. The simulated results compare favorably with the experimental results. Towards this objective, it is hoped that the present work would be of some practical value in industrial applications.

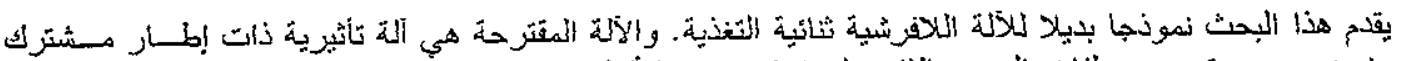

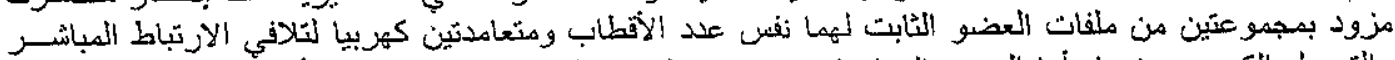

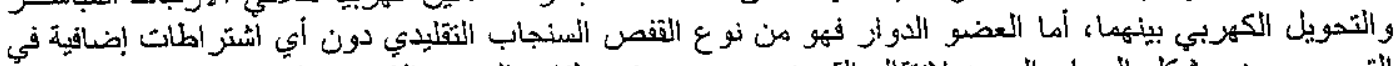

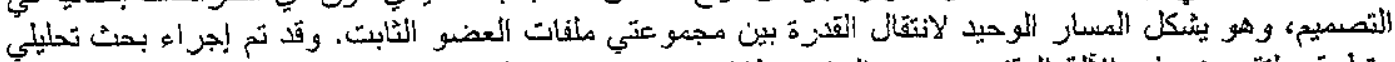

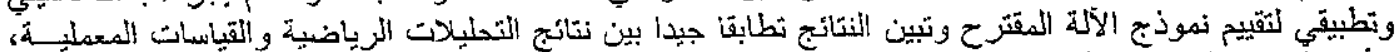

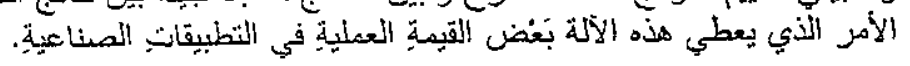

Keywords: Brushless doubly fed machine - Single-phase induction motor - Variable speed drive.

\section{INTRODUCTION}

The expression doubly-fed applies generally to electrical machines in which electrical power can be fed to or extracted from two accessible windings. There are different types of doubly-fed machines [1], however, brushless applies to only that type of a single frame with two sets of windings on its stator side. Brushless doubly-fed induction machine (BDFM) is a single-frame machine provided with two sets of stator windings which are wound in the same slots and share a common magnetic circuit $[2,13,10]$. One set of stator windings is referred to as the power windings, while the other set is referred to as the control windings [12]. The BDFM are mainly used for adjustable speed drives which possess an operating performance similar to conventional singly-fed induction machines powered from variable frequency inverters. Brushless doubly-fed machine is characterized by the advantage of its reduced power converter KVA rating. Whereas a singly-fed machine converter processes all active and required reactive power the doubly-fed machine converter handles only a reduced amount, dependent on the desired speed range. Additional advantages expected of the BDFM are controllable operation at exact or synchronous speed over a wide range, adjustable displacement power factor, reduced total harmonic distortion, and operation as a mains-fed induction machine in the event of converter failure [9].
In spite of these advantages, BDFM still have some drawbacks and design difficulties which should not be overridden. The main design difficulty of these machines is how to avoid direct transformer coupling between the two sets of stator windings. There are some established rules and conditions on stator/rotor pole combinations of these machines $[2,7,9,11]$. The rotor of a BDFM is basically constructed of shortcircuited cage windings; however, it is different from the conventional type of singly-fed induction motor. A sort of nested cage winding of different shapes were proposed $[3,9,13]$. The modifications are principally to satisfy the conditions imposed to eliminate direct transformer coupling between the two sets of stator windings. Some literature also highlighted instability problems associated with these machines and proposed certain solutions for such instabilities [6]. An extensive research effort is paid towards performance analysis $[2,7,13]$, dynamic simulation $[4,5]$ and control $[8,12,14]$ of these machines attempting to improve their operating performances for commercial applications.

By investigating the available literature reported about BDFM, it can be stated that they can offer a good economic solution for variable speed drives if their design complexities are overcome and operating performances are improved. So far, literature reported about BDFM is restricted to three-phase configuration, having two sets of three phase ac windings on the stator side. This paper investigates a 
ir, $\therefore, \cdots, \cdots$

two-winding single-phase machine with a conventional squirrel cage rotor as an alternative configuration for BDFM. The proposed machine consists of two sets of stator winding having the same number of poles and electrically perpendicular to each other to eliminate direct transformer coupling between them. In contrast to three-phase machine, there is no design conditions imposed on stator/rotor pole combinations since the two sets of windings are inherently decoupled. The interaction between the two windings is accomplished only through the rotor circuit. Simulated and experimental results are given.

\section{DESCRIPTION OF THE PROPOSED BDFM DRIVE}

The proposed BDFM is a single-frame machine with its stator provided with two sets of single-phase ac windings of the same number of poles and are located electrically perpendicular to each. One set of these windings is directly connected to the standard power mains of a fixed frequency. The second one is energized via a variable frequency inverter which permits bi-directional power flow to and from the machine. A schematic diagram for the proposed BDFM is shown in Fig.1.

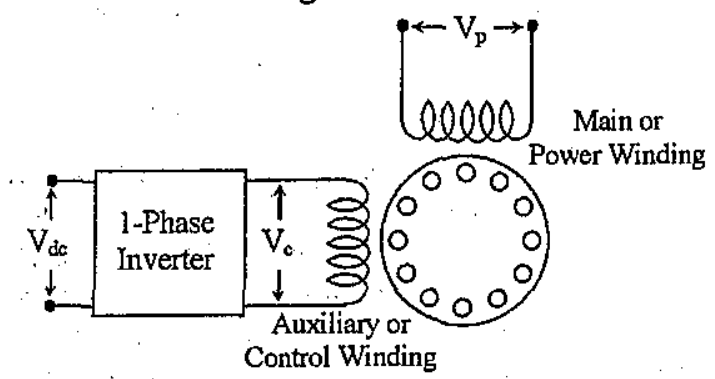

Fig. 1 Schematic diagram of the brushless proposed doubly-fed single-phase induction machine.

The experimental motor is, originally, a single-phase capacitor-start induction motor rewound with two symmetrical windings perpendicular to each other. Symmetric winding is not necessary; however it was prepared first before the complete analysis is conducted. The motor data and parameters are given in Appendix A.2. A mechanical switch is used to disconnect the starting capacitor and connect the variable frequency inverter to the auxiliary or control winding. An adjustable V/f, PWM power inverter is used to energize the control ' winding. All experimental results are obtained at a constant V/f ratio up to the rated frequency. Beyond the rated frequency, the voltage is maintained constant while frequency is varied.

\section{STEADY-STATE ANALYSIS}

The BDFM under investigation has three coupled circuits operating at different frequencies. The first is the main power circuit operating at the power supply frequency. The second is the auxiliary or control circuit operating at the inverter frequency. The third is the rotor circuit in which there are another two frequency components depending on the rotor slip relative to the rotating magnetic field of each stator winding. For this reason it becomes a bit difficult to establish an equivalent circuit to represent the steadystate operation. However, this machine may be conceived as two distinct induction machines operating in the same frame $[7,11]$. On these bases, it can be represented by a composed circuit like that shown in Fig. 2. It consists basically of two circuits; the first represents the main winding, while the second represents the control winding. Since the power and control windings are normally operating at different frequencies, they induce two current components with different frequencies in the rotor circuit. For this reason it was found both easier and better to represent the rotor by two separate equivalent circuits each one holds a single frequency current component.

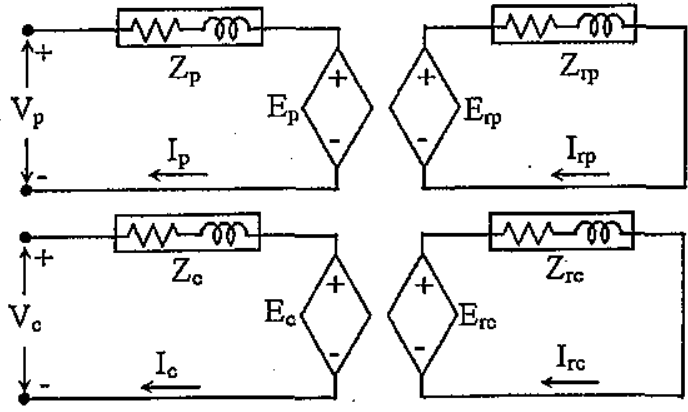

Fig. 2 The equivalent circuit of the proposed brushless doubly-fed single-phase induction machine.

The impedances of both main and control windings are represented as;

$Z_{p}=R_{p}+j \omega_{p} L_{p}$

$Z_{c}=R_{c}+j \omega_{c} L_{c}$

For being electrically perpendicular; they have no direct mutual coupling. The interaction between them is accomplished through the rotor circuit. Under running conditions, a back emf $E_{p}$ is induced in the main winding due to the current flowing in the rotor circuit. This back emf can be expressed as;

$E_{p}=\left(j \omega_{p} M_{p}\right) I_{r}=Z_{r p} I_{r}$

A similar back emf is induced in the control winding;

$\mathrm{E}_{\mathrm{c} i}=\left(\mathrm{j} \omega_{\mathrm{c}} \mathrm{M}_{\mathrm{c}}\right) \mathrm{I}_{\mathrm{r}}=\mathrm{Z}_{\mathrm{rc}} \mathrm{I}_{\mathrm{r}}$

However, $E_{p}$ and $E_{c}$ have different frequencies corresponding to their winding supply frequencies.

The two stator windings establish two rotating field components with two different speeds in the stator frame. The rotor follows these two fields with a different slip corresponding to each field. These two slip components can be expressed as;

$s_{p}=\left(\omega_{p}-P \omega_{r}\right) / \omega_{p}$
$s_{c}=\left(\omega_{c}-P \omega_{r}\right) / \omega_{c}$

Normally, the main field is faster than rotor speed and possessing a positive slip; however the control 
field could be faster with a positive slip or slower with a negative slip. Under the first condition, both main and control windings participate in the developed mechanical power. Under the second condition some power is extracted from the rotor and recovered back to the power mains by the control winding. For this reason the power inverter connected to this winding should be of a bidirectional power flow type.

Two emfs components are induced in the rotor circuit. The first $\mathrm{E}_{\mathrm{op}}$ is due to the power winding with a frequency corresponding to the slip between the field of that winding and rotor speed. This emf component can be expressed as;

$$
E_{\mathrm{rp}}=\left[j\left(\omega_{\mathrm{p}}-\mathrm{P} \omega_{\mathrm{r}}\right) \mathrm{M}_{\mathrm{p}}\right] \mathrm{I}_{\mathrm{p}}=Z_{\mathrm{rp}} I_{\mathrm{p}}
$$

The second component $E_{\mathrm{rc}}$ is due to the control winding with a frequency corresponding to the slip between the field of that winding and rotor speed. This emf component can be expressed as;

$$
\mathrm{E}_{\mathrm{rc}}=\left[\mathrm{j}\left(\omega_{\mathrm{c}}-\mathrm{P} \omega_{\mathrm{r}}\right) \mathrm{M}_{c}\right] \mathrm{I}_{\mathrm{c}}=\mathrm{Z}_{\mathrm{rc}} \mathrm{I}_{\mathrm{c}}
$$

Since two emf components with different frequencies are existing, two current components are flowing in the rotor circuit. For this reason it was found better to represent the rotor by two separate equivalent circuits each holding a single frequency current component.

The impedance of the first circuit $Z_{\mathrm{rp}}$ is expressed as;

$$
Z_{\mathrm{r}}=\mathrm{R}_{\mathrm{s}}+\mathrm{j}\left(\omega_{\mathrm{p}}-\mathrm{p} \omega_{\mathrm{r}}\right) \mathrm{L}_{\mathrm{r}}
$$

While the impedance of second circuit corresponding to the control winding is expressed as;

$$
Z_{r}=R_{r}+j\left(\omega_{c}-p \omega_{r}\right) L_{r}
$$

The introduced steady-state analysis model treats the $\mathrm{BDFM}$ as two separate machines in the same frame. On this basis it is possible to obtain the current, copper loss, mechanical power, and developed torque corresponding to each stator winding separately. The torque developed by the machine can be expressed as;

$$
T_{m}=\frac{1}{\omega_{r}}\left[I_{r p}^{2} R_{r}\left(\frac{1-S_{p}}{S_{p}}\right)+I_{r c}^{2} R_{r}\left(\frac{1-S_{c}}{S_{c}}\right)\right]
$$

which consists of two components corresponding to each stator winding.

\section{DYNAMIC ANALYSIS}

Dynamic analysis is based on a $d-q$ axis model expressed in a stationary reference frame. Since the control and main windings are perpendicular, their axes are chosen as the $\mathrm{d}$ and $\mathrm{q}$ axes respectively. Under running conditions, the main winding, which is located on the q-axis, is energized from the standard mains of which the voltage is expressed as; $\mathrm{v}_{\mathrm{qs}}=\sqrt{2} \mathrm{~V}_{\mathrm{p}} \sin \omega_{\mathrm{p}} \mathrm{t}$
The control winding, which is located on the d-axis, is energized from a bi-directional power flow variable frequency inverter with a fundamental voltage expressed as;

$\mathrm{v}_{\mathrm{ds}}=\sqrt{2} \mathrm{~V}_{\mathrm{c}} \sin \omega_{\mathrm{c}} \mathrm{t}$

The voltage equations of the $d-q$ model may be expressed as follows;

$$
\begin{aligned}
& \mathrm{v}_{\mathrm{qs}}=\mathrm{R}_{\mathrm{qs}} i_{\mathrm{qs}}+\rho \lambda_{\mathrm{qs}} \\
& \mathrm{v}_{\mathrm{ds}}=\mathrm{R}_{\mathrm{ds}} i_{\mathrm{ds}}+\rho \lambda_{\mathrm{ds}} \\
& \mathrm{v}_{\mathrm{qr}}^{\prime}=\mathrm{R}_{\mathrm{r}}^{\prime} i_{\mathrm{qr}}^{\prime}-\omega_{\mathrm{r}} \lambda_{\mathrm{dr}}^{\prime}+\rho \lambda_{\mathrm{qr}}^{\prime} \\
& \mathrm{v}_{\mathrm{dr}}^{\prime}=\mathrm{R}_{\mathrm{r}}^{\prime} i_{\mathrm{dr}}^{\prime}+\omega_{\mathrm{r}} \lambda_{\mathrm{qr}}^{\prime}+\rho \lambda_{\mathrm{dr}}^{\prime}
\end{aligned}
$$

If the current components are expressed in terms of their corresponding flux linkages, these voltage equations can be rewritten as;

$$
\begin{aligned}
& \mathrm{v}_{\mathrm{qs}}=\mathrm{R}_{\mathrm{qs}}\left(\lambda_{\mathrm{qs}}-\lambda_{\mathrm{mq}}\right) / \mathrm{L}_{\ell \mathrm{qs}}+\rho \lambda_{\mathrm{qs}} \\
& \mathrm{v}_{\mathrm{ds}}=\mathrm{R}_{\mathrm{ds}}\left(\lambda_{\mathrm{ds}}-\lambda_{\mathrm{md}}\right) / \mathrm{L}_{\ell \mathrm{ds}}+\rho \lambda_{\mathrm{ds}} \\
& \mathrm{v}_{\mathrm{qr}}^{\prime}=\mathrm{R}_{\mathrm{r}}^{\prime}\left(\lambda_{\mathrm{qr}}^{\prime}-\lambda_{\mathrm{mq}}\right) / \mathrm{L}_{\ell \mathrm{r}}^{\prime}-\omega_{\mathrm{r}} \lambda_{\mathrm{dr}}^{\prime}+\rho \lambda_{\mathrm{qr}}^{\prime} \\
& \mathrm{v}_{\mathrm{dr}}=\mathrm{R}_{\mathrm{r}}^{\prime}\left(\lambda_{\mathrm{dr}}^{\prime}-\lambda_{\mathrm{md}}\right) / \mathrm{L}_{\ell \mathrm{r}}^{\prime}+\omega_{\mathrm{r}} \lambda_{\mathrm{qr}}^{\prime}+\rho \lambda_{\mathrm{dr}}^{\prime}
\end{aligned}
$$

The developed electromagnetic torque is expressed as follows;

$$
\mathrm{T}_{\mathrm{em}}=\mathrm{P}\left(\lambda_{\mathrm{ds}} \mathrm{i}_{\mathrm{qs}}-\lambda_{\mathrm{qs}} \mathrm{i}_{\mathrm{ds}}\right)
$$

The mechanical equation can be written as;

$$
\mathrm{J} \rho \omega_{\mathrm{r}}=\mathrm{T}_{\mathrm{em}}-\mathrm{T}_{\text {load }}-\mathrm{T}_{\text {damp }}
$$

\section{SIMULATION AND EXPERIMENTAL RESULTS}

The introduced steady-state and dynamic models are implemented in a series of simulation programs using the general purpose simulation software MATLAB/SIMULINK to predict the machine operating performance. An experimental verification is carried-out using the experimental system described in part 2. In both analysis and experiments a constant V/f ratio up to the rated frequency and a constant voltage equals the rated value beyond rated frequency is used.

\subsection{Steady-State Results}

The steady-state performance is studied at constant load torque of $1.0 \mathrm{Nm}$. The winding current, input power, copper losses, developed mechanical power and torque are determined for each winding and represented as a function of both the frequency of the control winding and rotor speed.

Figure 3 shows the simulated and measured currents drawn by both the main winding $I_{p}$ and control winding $I_{c}$, as functions of control frequency and motor speed respectively. The current of the main winding is quite high at low speeds and gets lower by increasing the motor speed; however this is a characteristic of the induction motor. The current of 
the control winding has a moderate variation over the entire speed range.

Figure 4 demonstrates the simulated and measured power drawn by both the main winding $P_{\text {inp }}$ and control winding $P_{\text {inc }}$ as well as the total power drawn by the motor over the entire speed range. It is of importance to note that the control winding has a negative power at low speeds this, the function of this winding is to extract some power from the machine and recover it back to the power mains to control the motor speed. At high speeds this winding provides a positive power to the motor to increase the speed.

Figure 5 represents the copper losses dissipated by the main, control and rotor windings as well as the total copper losses which represent the summation of those components. The difference of these copper loss components has no specific means other than the winding losses are proportional to the square of their respective currents. However, all components are high at low speeds, decrease at high speeds, and have their minimum values at the motor rated frequency. The high copper loss at low speeds seems to be a drawback of this method to control the motor speed.

Figure 6 represents the mechanical power developed by the main and control windings as well as the total mechanical power developed by the machine. It is observed that the control winding exhibits a negative mechanical power over a wide range of operating speeds. This negative power is essential to control the motor speed.

Figure 6 represents the efficiency of the machine as a function of control frequency and rotor speed respectively. The efficiency is low at low speeds and is improved as the motor speed rises. It should be remembered that the machine under investigation is a fractional horsepower machine with normal low efficiency. The low efficiency here is attributed mainly to the high copper losses associated with the main winding at low speeds. This machine efficiency can be improved by using a main winding with lower resistance.

Figure 8 represents the torque developed by the main and control windings as well as the total electromagnetic torque developed by the machine. It is also observed that the control winding exhibits a negative torque over a wide range of operating speeds. This negative torque is essential to control the motor speed,

Figure 9. represents the simulated and measured speed as a function of the control frequency at constant load torque. The two variables are approximately proportional up to the rated frequency, after which, the rate of speed increase decline. This is because a constant dc-link voltage is used for the inverter beyond the rated frequency.
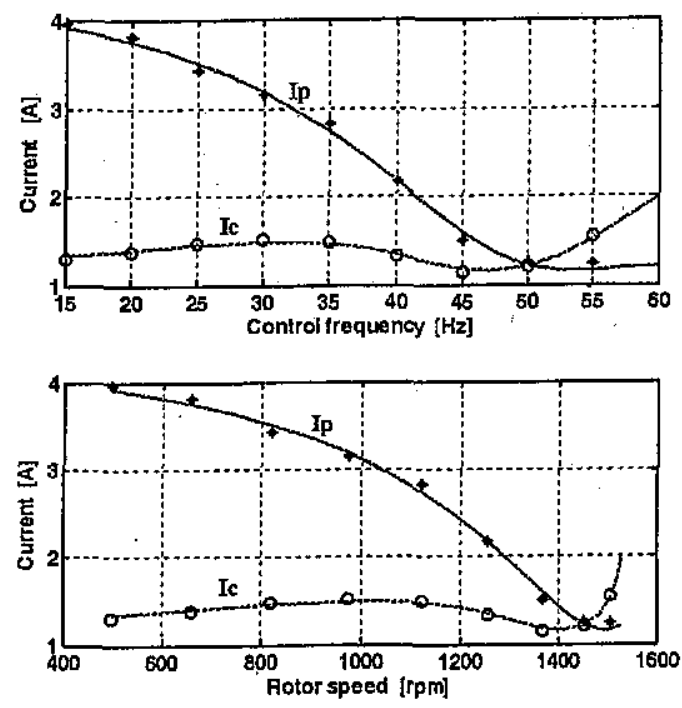

Fig. 3 Stator current
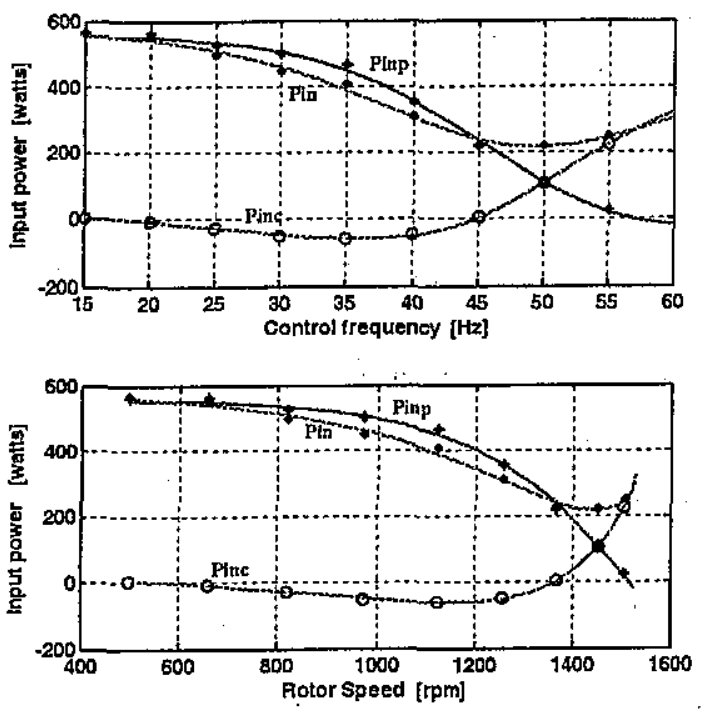

Fig. 4 Input Power
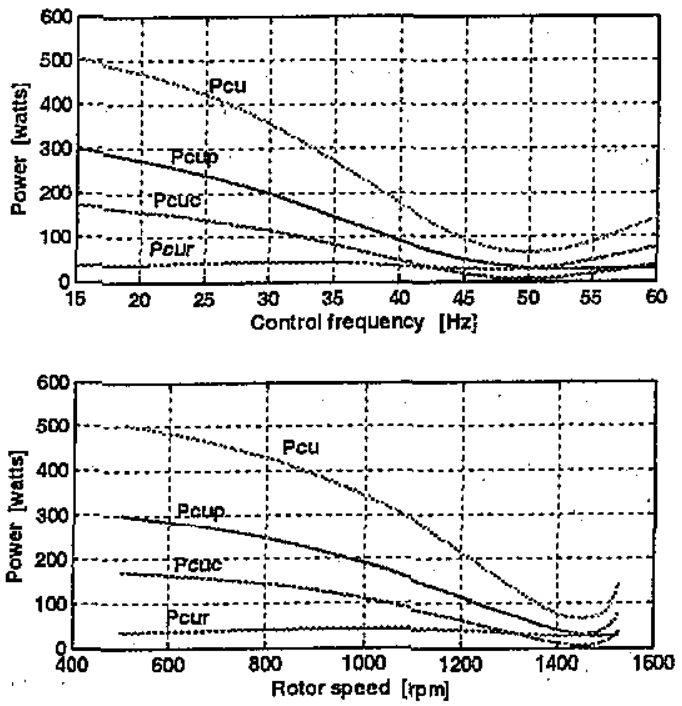

Fig. 5 Copper Loss 

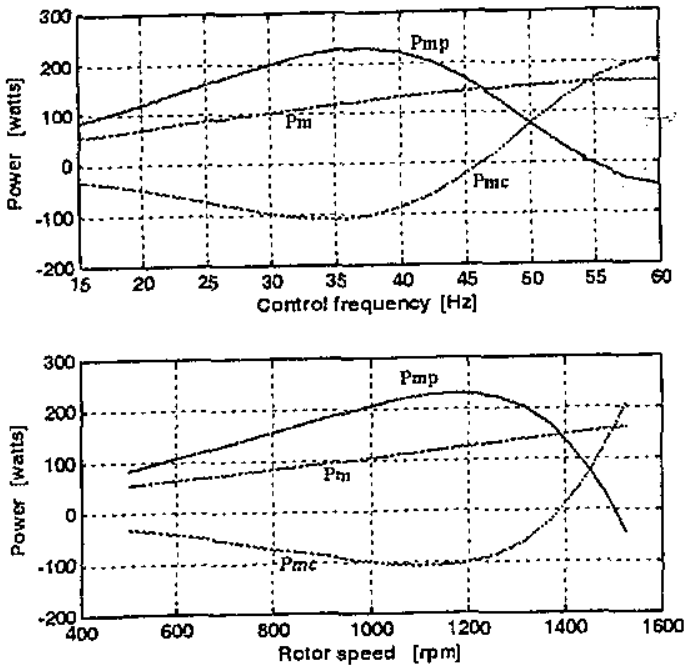

Fig. 6 Mechanical power
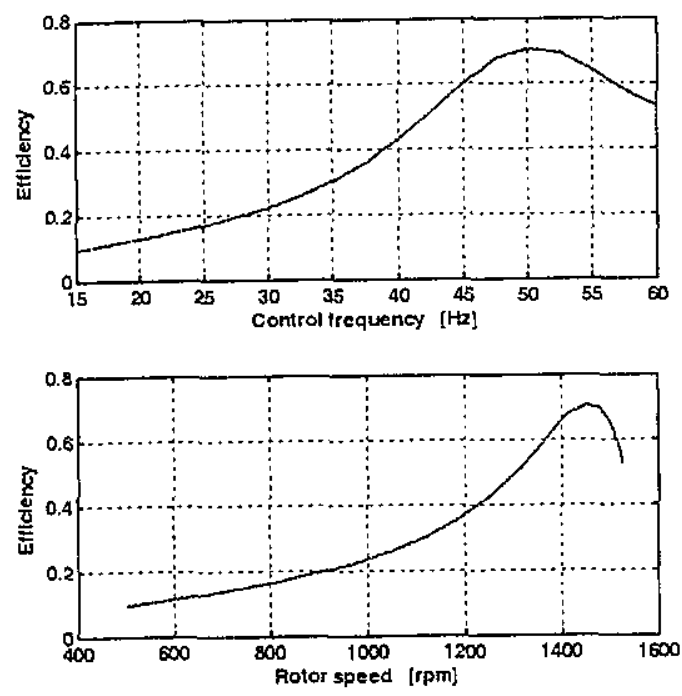

Fig. 7 Efficiency
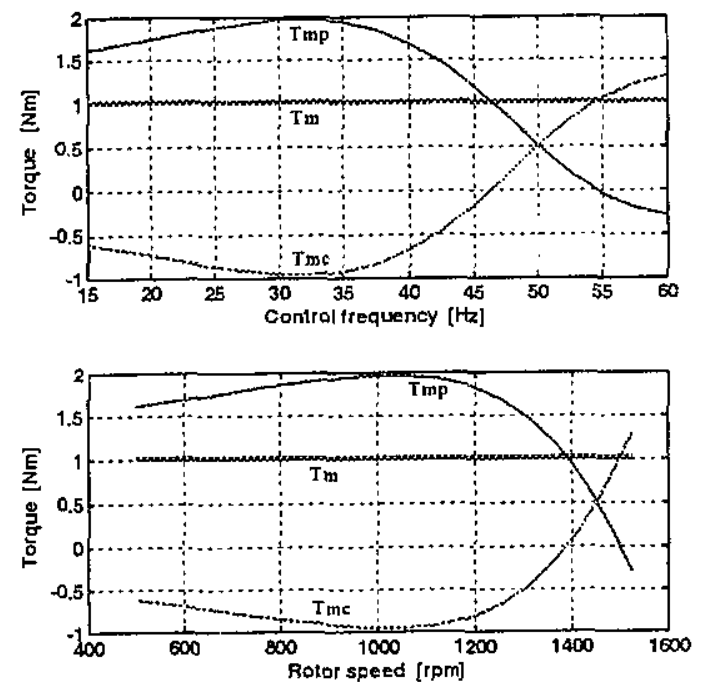

Fig. 8 Developed torque

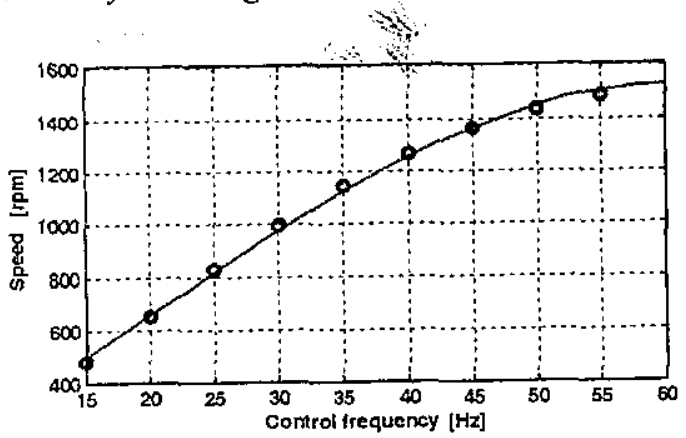

Fig. 9 Speed/frequency curve variation at a constant load torque of $1 \mathrm{Nm}$

\subsection{Dynamic Results}

The motor dynamic response is tested for switchingon the control winding while it was originally running solely with its main winding energized. After switching-on the control winding, it starts to takeover its duty for reducing the motor speed. Figure 10 represents the simulation results for main winding current $I_{\mathrm{qs}}$ and control winding current $I_{d s}$ for the motor when it was originally running solely with its main winding, then the control winding is switchedon at a frequency equals to $25 \mathrm{~Hz}$. The current of the control winding settles at constant level after a short transient period, while the main winding current increases. Due to the increase of the main winding slip, its current increases, which is a characteristic of the induction motor. The corresponding experimental results are shown in Fig. 11.

Figure 12 shows the simulated results for two axes current components $I_{\mathrm{qr}}$ and $\mathrm{I}_{\mathrm{dr}}$ induced in the rotor circuit for the same condition. It is clear from the figure that the switch-on of the control winding is reflected also on these current components as shown in this figure. Since there are two slip components corresponding to the two rotating electromagnetic fields, the rotor current has two components with two frequencies superimposed one over the other.

The simulation results for the instantaneous developed torque $T_{m}$, average torque $T_{a v}$ and motor speed response are shown in Fig. 13. It is observed that the instantaneous torque is pulsating before and after switching the control winding. Before switching there is only a single winding producing a pulsating electromagnetic field in the air gap, which develops a pulsating torque with an average positive value as shown. After switching, there are two pulsating electromagnetic fields in the air gap with two different frequencies. Each field produces a corresponding torque component. The instantaneous summation of these two torque components represents the instantaneous torque shown in Fig. 13. The average torque is the same before and after switching, except a short transient period just after switching during which load torque is extracted from the rotor inertia. 
The rotor speed obtained by simulation is also shown in Fig. 13. It shows that the motor speed decreases by introducing the control winding with a reduced frequency. This is due to the negative torque developed by the control winding which reduces the motor speed. The measured speed response corresponding to this condition is shown in Fig. 14.
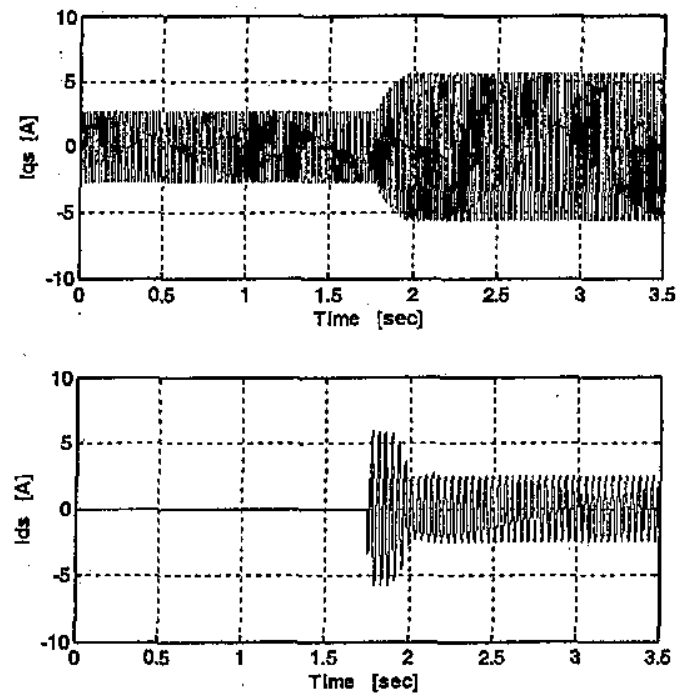

Fig. 10 Stator current (Simulation Results)

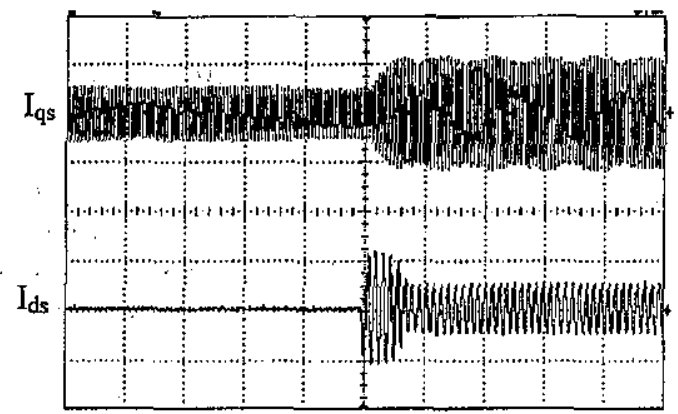

Fig. 11 Stator current (Experimental Results) (Horizontals: $0.5 \mathrm{Sec} / \mathrm{div}$, Vertical: $5 \mathrm{~A} / \mathrm{Div}$ )
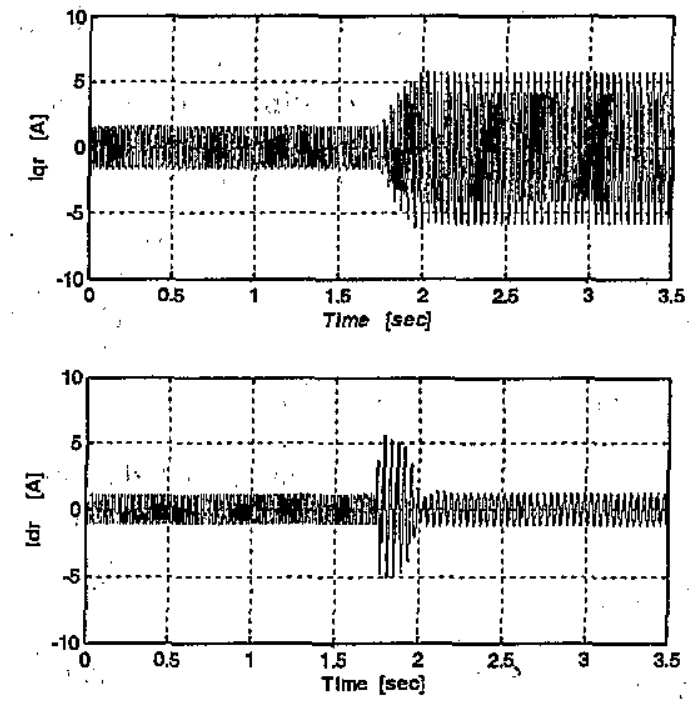

Fig. 12 Rotor current (Simulation Results)
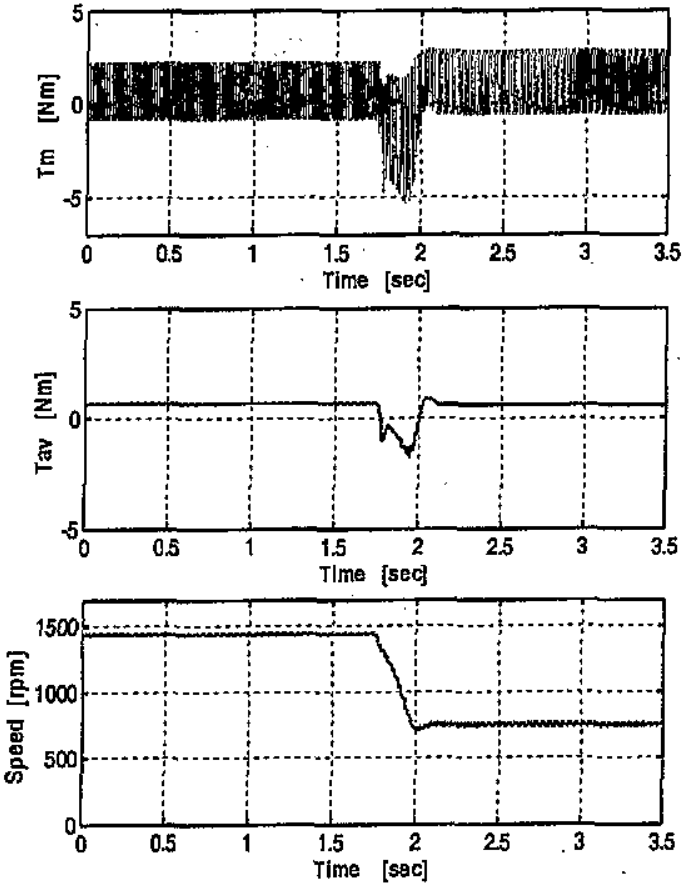

Fig. 13 Developed torque and speed (Simulation Results)

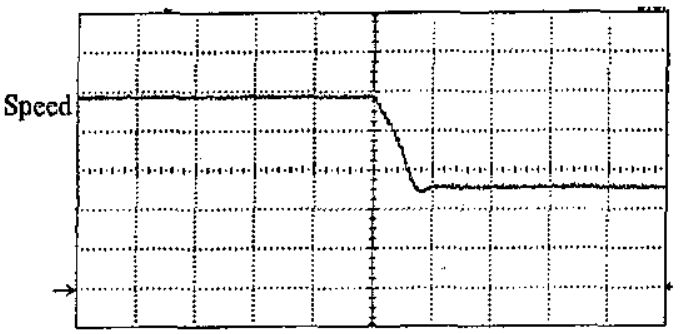

Fig. 14 Motor speed (Experimental Results) (Horizontals: $0.5 \mathrm{Sec} / \mathrm{div}$, Vertical: $300 \mathrm{rpm} / \mathrm{Div}$ )

\section{CONCLUSION}

An alternative configuration for $B D F M$ has been presented. Steady-state and dynamic behaviors of the proposed machine have been studied under different operating conditions. The results show that low speeds are obtained at reduced control frequencies due to extracting a part of the rotor power and generating a negative torque by the control winding. When the control frequency approaches or exceeds that of the main winding, control winding provides a secondary port for input power and contributes an extra positive torque component. A wide speed range has been obtained at constant load torque which is difficult to be attained with other methods like applied voltage control. The proposed BDFM is characterized by its reduced inverter KVA and it is suitable for small power variable speed drive applications. The main drawback of the proposed method is the relatively low efficiency at low speeds; however, it may be improved by using a main winding of low resistance. 


\section{REFERENCES}

[1] B. Hopfensperger, and D.J. Atkinson, "DoublyFed AC. Machines: Classification and Comparison", European Power Electronics Conference, EPE 2001, PP P1-P17

[2] F. Rüncos, R.Carlson, N. Sadowski, and P. KuoPeng, "Performance Analysis of a Doubly Fed Twin Stator Cage Induction Generator", 16th Int. Conf. on Electrical Machines (ICEM 2004) 5-8 Sept 2004, Poland

[3] P.C. Roberts, R.A. McMahon, P.J. Tavner, and J.M. Maciejowski, T.J. Flack, X. Wang, "Performance of Rotors in a Brushless DoublyFed Induction Machine (BDFM)", 16th Int. Conf. on Electrical Machines (ICEM 2004) 5-8 Sept 2004, Poland

[4] Yang Xiangyu, Qin Zuze, and Li Qingfu, "Fast Digital Simulation of Inverter-Brushiess DoublyFed Machines for Adjustable Speed Drive System", $5^{\text {th }}$ Int. Conf. on Electrical Machines and Systems, ICEMS 2001. 18-20 Aug. 2001, PP 463-466

[5] Xie Lun, Sun Yikang, Ding Yung Yunshi, Wang Jing, Wang Song, Du Cang, and Sheng Xiangyuan, "The Research of Brushless DoublyFed AC Excited Induction Motor Drive", $5^{\text {th }}$ Int. Conf. on Electrical Machines and Systems, ICEMS 2001. 18-20 Aug. 2001, PP 972-975

[6] P.C. Roberts, T.J. Flack, J. M. Maciejowski, and R. A. McMahon, "Two Stabilising Control Strategies for Brushless Doubly-Fed Machine (BDFM)", Int. Conf. on Power Electronics, Machines and Drives, 2002. (Conf. Publ. No. 487), PP 341-346

[7] M. Boger and A. Wallace, "Performance Capability Analysis of the Brushless Doubly-Fed Machine as a Wind Generator", $7^{\text {th }}$ Int. Conf. on Electrical Machines and Drives, 11-13 Sep 1995 (Conf. Publ. No. 412), PP 458-461

[8] D. Zhou, R. Spee, G.C. Alexander, and A. K. Wallace, "A Simplified Method for Dynamic Control of Brushless Doubly-Fed Machines", Int. Conf. on Industrial Electronics, Control, and Instrumentation IECON, 5-10 Aug. 1996, PP 946-951

[9] S. Willaimson, A. C. Ferreira, and A. K. Wallace, "Generalised Theory of Brushiess Doubly-Fed Machine. Part 1: Analysis", IEE Proc. Elect. Power Appl., Vol. 144, No. 2, March 1997, PP 111-122

[10] S. Willaimson, and A. C. Ferreira, "Generalised Theory of Brushless Doubly-Fed Machine. Part 2: Model Verification and Performance", IEE Proc. Elect. Power Appl., Vol. 144, No. 2, March 1997, PP 123-129

[11] P C Roberts, R A McMahon, P J Tavnery, J M Maciejowski, and $\mathrm{T} \mathrm{J}$ Flack, "An equivalent circuit for the Brushless Doubly Fed Machine
(BDFM) Including Parameter Estimation and Experimental Verification", IEE Journal 2001

[12] Huang Shoudao, Wang Yi, Wang Yaonon, and Ren Guangfa, "Active and Reactive Power Control for Brushless Doubly-Fed Machine", The 4th Int. Conf. Power Electronics and Motion Control Conference, IPEMC 2004, 14-16 Aug. 2004, PP 640-644

[13] F. Runcos, R. Carlson, A. M. Oliverira, P. KuoPeng, and N. Sadowski, "Performance Analysis of a Brushless Double Fed Cage Induction Genarator", Nordic Wind Power Conference 1-2 March 2004, Chalmers University of Technology, PP 1-8

[14] Huang Shpudao, Huang Keyuan, Zhou Lawu and Lai Lieen, "A Study of the Control Strategy on Rotor Field Orientation for Brushless DoublyFed Machine", $3^{\text {rd }}$ Int. Power Electronics and Motion Control Conf. PIEMC 2000, 15-18 Aug. 2000, PP 508-513

\section{APPENDICES}

\section{A.1. List of Symbols:}

$i_{d s}, i_{q s} \quad d, q$ axis stator currents.

$i_{d r}, i_{q r} \quad d, q$ axis rotor currents.

$\mathrm{J}$ Moment of inertia of rotating parts.

$\mathrm{L}_{\ell \cdot} \quad$ Rotor leakage inductance of both axes.

$\mathrm{L}_{\mathrm{md}}, \mathrm{L}_{\mathrm{mq}}, \mathrm{d}, \mathrm{q}$ axis mutual inductances.

$\mathrm{L}_{\ell d \mathrm{~s}}, \mathrm{~L}_{\ell s \mathrm{q}}, \mathrm{d}, \mathrm{q}$ axis stator leakage inductances.

$P \quad$ Number of pair poles.

$R . \quad$ Rotor resistance.

$\mathrm{R}_{\mathrm{ds}}, \mathrm{R}_{\mathrm{q}}, \quad \mathrm{d}, \mathrm{q}$ axis stator resistances.

$T_{\text {em }}, T_{\text {load }}, T_{\text {damp }}$ Electromagnetic, load and damp torque components.

$V_{c} \quad$ The rms voltage of the control winding.

$V_{p} \quad$ The rms voltage of the main winding

$v_{d s}, v_{q s}, d, q$ axis stator voltages.

$\mathrm{v}_{\mathrm{dr}}, \mathrm{v}_{\mathrm{qr}}, \quad \mathrm{d}, \mathrm{q}$ axis rotor voltages.

$\omega_{p}$ The angular frequency of the main winding

$\omega_{c}$ The angular frequency of the control winding.

$\rho \quad$ Derivative operator $\mathrm{d} / \mathrm{dt}$

$\lambda_{d s}, \lambda_{q s}, d, q$ axis stator flux linkages.

$\lambda_{\mathrm{dr}}, \lambda_{\mathrm{rq}}, \quad \mathrm{d}, \mathrm{q}$ axis rotor flux linkages.

$\omega_{\mathrm{r}} \quad$ Rotor speed.

A.2. Motor Data and Parameters:

$220 \mathrm{~V}, 0.25 \mathrm{kw}, 50 \mathrm{~Hz}$, 4-pole, $3.1 \mathrm{~A}$, capacitor-start single-phase induction with a starting capacitor of 20 $\mu \mathrm{F}$. The motor is rewound with two symmetrical windings having the following the following parameters;

$$
\begin{aligned}
& R_{q s}=R_{d s}=19.6 \Omega, L_{t q s}=L_{t d s}=0.0697 \mathrm{H} \\
& R_{r}^{\prime}=14.6 \Omega, L_{t r}^{\prime}=0.0697 \mathrm{H}, \\
& L_{m q}=L_{m d}=0.5306 \mathrm{H}, J=0.005 \mathrm{~kg} \cdot \mathrm{m}^{2}
\end{aligned}
$$

